\title{
Assessment of Hip Involvement in Patients With Ankylosing Spondylitis: The Reliability Between the HIMRISS and BASRI-Hip System
}

\author{
Siliang Man \\ Beijing Jishuitan Hospital \\ Liang Zhang \\ Beijing Jishuitan Hospital \\ Tao Bian \\ Beijing Jishuitan Hospital \\ Hongchao Li \\ Beijing Jishuitan Hospital \\ Zhuyi Ma \\ Beijing Jishuitan Hospital \\ Yixin Zhou ( $\nabla$ orthoyixin@yahoo.com ) \\ Beijing Jishuitan Hospital
}

\section{Research Article}

Keywords: ankylosing spondylitis, hip, classification system, reliability

Posted Date: February 26th, 2021

DOI: https://doi.org/10.21203/rs.3.rs-242944/v1

License: (c) (i) This work is licensed under a Creative Commons Attribution 4.0 International License. Read Full License

Version of Record: A version of this preprint was published at BMC Musculoskeletal Disorders on August 17th, 2021. See the published version at https://doi.org/10.1186/s12891-021-04502-3. 


\section{Abstract}

Background. The aim is to test the reliability and validity of the Hip Inflammation MRI Scoring System (HIMRISS) in assessing hip involvement of AS patients at different stages of the bath ankylosing spondylitis radiology index (BASRI-hip) scoring system.

Methods. Fifty-two outpatients with ankylosing spondylitis(AS) were included in this study. The subjects' data includes demographics, clinical characteristics, disease activity score, and functional index. Based on the Harris hip scoring (HHS) of involved hip and BASRI-hip score, we devided these patients into no hip involvement group(HHS $\geq 80$ and $B A S R I \leq 1)(G r o u p ~ A)$, mild hip involvement subgroup (BASRI=2 or BASRI $\leq 1$ and $H H S \leq 79)$ (Group B) and moderate to advanced hip involvement subgroup (BASRI $\geq 3$ ) (Group C). Data was analyzed statistically by SPSS software.

Results. In total of 44 patients (88 hips), group A consisted of 21 hips, group B consisted of 42 hips and group C consisted of 25 hips. The test-retest intraclass correlation coefficients (ICCs) in four raters were 0.955 0.977 and interrater ICC was 0.993. HIMRISS correlated moderately with the Bath Ankylosing Spondylitis Disease Activity Index (BASDAI) ( $r=0.540, p<0.001)$, the Bath ankylosing spondylitis functional index (BASFI) ( $r=0.581$, $p<0.001)$, ASDAS-ESR ( $r=0.604, p<0.001)$ and Ankylosing Spondylitis Disease Activity Score(ASDAS)- $C$ reactive protein (CRP) ( $r=0.575, p<0.001)$. HIMRISS in group $B$ and $C$ was significantly higher than that in group $A: 29.38 \rrbracket 17.00 \rrbracket 40.94 \rrbracket v s ~ 14.50 \rrbracket 11.38 \rrbracket 22.25 \rrbracket, p=0.009 ; 38(31.13 \rrbracket 64.38 \rrbracket v s$ $14.50 \otimes 11.38 \bowtie 22.25), p<0.001$.

Conclusions. HIMRISS applied to patients with AS demonstrated a satisfactory reliability, which means it is a reliable quantitive assessment tool for evaluating early hip involvement in patients with AS.

\section{Introduction}

Hip involvement is common in patients with ankylosing spondylitis(AS) $\nabla 1-3$ \and is associated with severe functional impairment, work disability, a compromised psychological status and quality of life $\$ 4-6 \rrbracket$. When hip involvement progresses to an advanced symptomatic stage, total hip arthroplasty (THA) which is acknowledged as the well-accepted treatment currently will be conducted, and a number of authors have reported their results using cemented or cementless techniques $\$ 7-12 \bigotimes$. Unfortunately, hip prostheses with various exclusive designs have a limited life span, and revision surgeries are often needed periodically. Consequently, it is extremely crucial to estalish a comprehensive and reliable system for accurate and early diagnosis of hip involvement in AS patients.

In previous studies, the diagnosis of hip involvement has been focused on clinical findings and radiographic changes. The symptoms of hip involvement symptoms are insidious onset and there is even no symptoms in the early course of the disease. The bath ankylosing spondylitis radiology index (BASRI-hip) which has been proved to be an objective and reliable grading system is the most widely used radiographic classification system to assess severity and progression of hip involvement in patients with AS $₫ 13,14-16$. Conventional radiographs can display postinflammatory structural injuries and are unable to reflect some key histopathological changes, including subchondral bone marrow edema(BME) and synovitis $₫ 17-$ 18区. As a result, radiographs may underestimate the frequency of hip involvement leading to a diagnosis delay.

Magnetic resonance imaging (MRI) provides excellent visualization of bones and soft tissues and is the only imaging tool which is capable of visualizing bone marrow inflammation, a hallmark of AS $₫ 19-20 \bigotimes$. In previous studies, however, the application of MRI imaging is mainly focused on sacroiliac joints and spine of patients with AS. There is few data of the changes of hip MR imaging $21-23 \otimes$. The Hip Inflammation MRI Scoring System (HIMRISS) was developed by using the data from a trial of intraarticular steroid therapy for osteoarthritis(OA), which is based on the concept that scoring of hip OA most usefully emphasizes the evidence of active inflammation $824-25 \rrbracket$. The feasibility and the reliability of this imaging system have been fully validated in the setting of hip OA. Zheng et al introduced HIMRISS into the evaluations of spondyloarthritis (SpA), and the

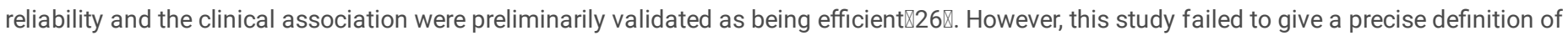
clinical or radiographic hip involvement to these patient population. This study was aim to test the reliability and validity of HIMRISS for assessing hip involvement of AS patients at different stages of BASRI-hip scoring system.

\section{Materials And Methods}

\section{Patient demographics and enrollment}

Fifty-two AS outpatients who were admitted to the department of rheumatology and the department of adult joint reconstruction surgery in our institute from February 2018 to June 2019 were enrolled in this study. The inclusion criteria were as follows: (1) diagnoses of AS were made according to the 1984 modified New York criteria囚27区; (2) the age of the patients ranged from 18 to 45 years. Exclusion criteria that any selected patients with any of the followings: (1) systemic diseases of the muscular of nervous systems, (2) history of congenital or childhood disease, surgery, deep infection, trauma, and tumor of hip; (3) lower extremity replacement or amputation other hip joint; (4) MRI contraindications (e.g. pacemaker, metal implants, pregnancy, claustrophobia).

The subjects' demographics and clinical characteristics included gender, body mass index (BMI), age at outpatient visit, age at onset of AS, duration of AS, diagnosis delay, family history, medication status and extra-articular manifestations (EAMs) (current or past) including uveitis, psoriasis and inflammatory bowel disease (IBD). Disease activity was assessed respectively using the Bath Ankylosing Spondylitis Disease Activity Index (BASDAI) 


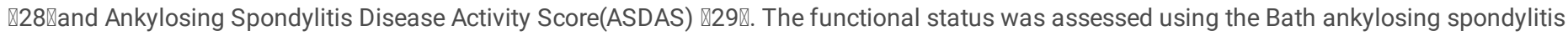
functional index (BASFI) 『30区. The patient-reported outcomes (PROs) were assessed by using the Ankylosing Spondylitis Quality of Life (ASQoL) scales $₫ 31$ \and the short form-12(SF-12) $₫ 32 \rrbracket$. The use of the medications including NSAIDs and DMARDs was recorded, and the patients who had taken treatment agents for one year or longer were considered as sustained users. These data for clinical characteristics were collected and evaluated independently by two rheumatologists (L.H.C. and M.S.L.) who had not participated in radiographic evaluations conducted from a face-to-face questionnaire and medical records. The Harris hip scoring (HHS) system $₫ 33 \otimes$ was directly evaluated by orthopedic surgeons (Z.L. and H.Y.) at the time of outpatient consultation. On the 100-point scale, a score of 90 points or more is defined as an excellent outcome; 80 to 89 points, a good outcome; 70 to 79 points, a fair outcome; and 70 points or less, a poor outcome.

Laboratory data such as human leukocyte antigen (HLA-B27) status, serum erythrocyte sedimentation rate (ESR), high sensitive $\mathrm{C}$ reactive protein (CRP) and CRP level were also measured at enrollment.

The results of these clinical and laboratory parameters are provided in Table 1. 
Table 1

Patient demographics, clinical and laboratory parameters of AS patients on different stages of hip involvement

\begin{tabular}{|c|c|c|c|c|c|c|c|c|}
\hline & Total AS patients & Group $A(n=21)$ & Group $B(n=42)$ & Group $C(n=25)$ & $P$ & Adjuste & P value & \\
\hline & & & & & & $A-B$ & $A-C$ & B-C \\
\hline $\begin{array}{l}\text { Male gender, } \\
\mathrm{n}(\%)\end{array}$ & $72(81.8 \%)$ & $20(95.2 \%)$ & $33(78.6 \%)$ & $19(76.0 \%)$ & 0.175 & & & \\
\hline $\begin{array}{l}\text { Age at } \\
\text { outpatient } \\
\text { visit (years) }\end{array}$ & $30.00(25.25,34.75)$ & $32.00(30.00,39.00)$ & $\begin{array}{l}30.00(25.50- \\
34.25)\end{array}$ & $\begin{array}{l}28.50(25.00- \\
35.00)\end{array}$ & 0.147 & & & \\
\hline $\begin{array}{l}\text { Age at onset } \\
\text { (years) }\end{array}$ & $23.00(19.00,26.00)$ & $25.00(23.00,28.00)$ & $22.00(18.00,27.25)$ & $21.50(17.00,24.00)$ & $0.005^{*}$ & 0.093 & $0.004^{*}$ & 0.390 \\
\hline $\begin{array}{l}\text { Disease } \\
\text { duration } \\
\text { (years) }\end{array}$ & $6.50(2.00,10.50)$ & $6.00(2.00,11.00)$ & $6.00(2.00,9.00)$ & $7.00(2.00,11.00)$ & 0.812 & & & \\
\hline $\begin{array}{l}\text { Diagnosis } \\
\text { delay (years) }\end{array}$ & $2.00(0.25,8.00)$ & $1.00(0.00,6.00)$ & $2.00(0.00,8.00)$ & $2.00(1.00,10.50)$ & 0.233 & & & \\
\hline $\begin{array}{l}\text { Family } \\
\text { history, n (\%) }\end{array}$ & $27(30.7 \%)$ & $6(28.6 \%)$ & $9(21.4 \%)$ & $12(48.0 \%)$ & 0.081 & & & \\
\hline EAMs, n (\%) & $14(15.9 \%)$ & $1(4.8 \%)$ & $7(16.7 \%)$ & $6(24.0 \%)$ & 0.213 & & & \\
\hline Uveitis, n (\%) & $3(3.4 \%)$ & $0(0.0 \%)$ & $0(0.0 \%)$ & $3(12.0 \%)$ & $0.033^{*}$ & 1 & 0.239 & $0.048^{*}$ \\
\hline IBD, n (\%) & $7(8.0 \%)$ & $1(4.8 \%)$ & $5(11.9 \%)$ & $1(4.0 \%)$ & 0.595 & & & \\
\hline $\begin{array}{l}\text { Psoriasis, } \mathrm{n} \\
\text { (\%) }\end{array}$ & $4(4.4 \%)$ & $0(0.0 \%)$ & $2(4.8 \%)$ & $2(8.0 \%)$ & 0.570 & & & \\
\hline $\begin{array}{l}\text { Use of } \\
\text { NSAIDs, n (\%) }\end{array}$ & $82(93.2 \%)$ & $19(90.5 \%)$ & $39(92.9 \%)$ & $24(96.0 \%)$ & 0.327 & & & \\
\hline $\begin{array}{l}\text { Use of } \\
\text { DMARDs, n } \\
(\%)\end{array}$ & $36(40.9 \%)$ & $8(38.1 \%)$ & $17(40.5 \%)$ & $11(44.0 \%)$ & 0.922 & & & \\
\hline $\mathrm{BMI}$ & $25.95(22.86,29.09)$ & $27.12(23.12,29.93)$ & $25.81(22.86,29.36)$ & $25.95(19.59,28.98)$ & 0.752 & & & \\
\hline $\begin{array}{l}\text { HLA-B27 } \\
\text { positivity, n } \\
(\%)\end{array}$ & $80(90.9 \%)$ & $21(100.0 \%)$ & $38(90.5 \%)$ & $21(84.0 \%)$ & 0.165 & & & \\
\hline $\mathrm{ESR}(\mathrm{mm})$ & $25.50(13.00,38.00)$ & $13.00(10.00,24.50)$ & $25.00(13.00,39.25)$ & $29.00(25.00,41.25)$ & $\begin{array}{l}< \\
0.001^{*}\end{array}$ & $0.016^{*}$ & $\begin{array}{l}< \\
0.001^{*}\end{array}$ & 0.296 \\
\hline $\mathrm{CRP}(\mathrm{mg} / \mathrm{L})$ & $14.80(9.30,27.80)$ & $13.20(6.60,15.56)$ & $14.30(5.28,27.80)$ & $24.20(12.70,53.80)$ & $0.003^{*}$ & 0.610 & $0.003^{*}$ & $0.032^{*}$ \\
\hline $\mathrm{hsCRP}(\mathrm{mg} / \mathrm{L})$ & $13.54(4.60,28.17)$ & $7.70(4.93,20.44)$ & $12.20(3.42,29.49)$ & $25.96(8.83,34.24)$ & $0.031^{*}$ & 0.869 & $0.031^{*}$ & 0.179 \\
\hline ALB $(\mathrm{g} / \mathrm{L})$ & $45.50(43.00,47.45)$ & $44.90(41.30,46.80)$ & $46.30(43.95,47.70)$ & $43.90(43.00,46.65)$ & 0.134 & & & \\
\hline $\mathrm{HGB}(\mathrm{g} / \mathrm{L})$ & $142.00(133.00,150.00)$ & $\begin{array}{l}145.00(141.00- \\
159.00)\end{array}$ & $\begin{array}{l}143.00(131.50- \\
152.00)\end{array}$ & $\begin{array}{l}141.00(130.00- \\
149.00)\end{array}$ & 0.123 & & & \\
\hline BASDAI & $3.20(1.80,5.35)$ & $2.00(1.40,3.00)$ & $3.40(1.65,5.25)$ & $4.60(3.20,5.80)$ & $\begin{array}{l}< \\
0.001^{*}\end{array}$ & 0.070 & $\begin{array}{l}< \\
0.001^{*}\end{array}$ & $0.023^{*}$ \\
\hline BASFI & $1.60(0.73,2.60)$ & $0.70(0.60,1.30)$ & $1.80(0.80,2.90)$ & $2.00(1.60,2.83)$ & $\begin{array}{l}< \\
0.001^{\star}\end{array}$ & $0.001^{*}$ & $\begin{array}{l}< \\
0.001^{*}\end{array}$ & 0.214 \\
\hline ASQOL & $6.00(2.00,8.00)$ & $2.00(2.00,3.00)$ & $6.00(2.75,8.00)$ & $7.00(6.00,11.75)$ & $0.001^{*}$ & $0.011^{*}$ & $0.001^{*}$ & 0.541 \\
\hline
\end{tabular}

$\star P<0.05, \mathrm{AS}=$ ankylosing spondylitis, EAMs = extra-articular manifestations, IBD $=$ inflammatory bowel disease, NSAIDs $=$ nonsteroidal antiinflammatory drugs, DMARDs = disease modifying anti-rheumatic drugs, BMI = bone mass density, HLA-B27 = human leucocyte antigen-B 27, ESR $=$ erythrocyte sedimentation rate, $\mathrm{CRP}=\mathrm{C}$ reactive protein, $\mathrm{hsCRP}=$ high sensitive $\mathrm{C}$ reactive protein, $\mathrm{ALB}=$ albumin, $\mathrm{HGB}=$ hemoglobin, $\mathrm{BASDAl}=$ Bath ankylosing spondylitis disease activity index, BASFI = Bath ankylosing spondylitis functional index, ASQOL $=$ ankylosing spondylitis quality of life, ASDAS = Ankylosing Spondylitis Disease Activity Score, SF-12 PCS = short form-12 physical component summary, SF-12 MCS = short form-12 mental component summary, HHS = Harris hip score, BASRI-Hip = the bath ankylosing spondylitis radiology hip index

Group A represents the hips with no hip involvement (HHS $\geq 80$ and BASRI $\leq 1)$, group B represents the hips with mild hip involvement (BASRI $=2$ or $\mathrm{BASRI} \leq 1$ and $\mathrm{HHS} \leq 79)$ and Group $\mathrm{C}$ represents the hips with advanced hip involvement $(\mathrm{BASRI} \geq 3)$

The value of continuous variables was presented as median and quartile (25-75\%) and the categorical variables were based on presented as number plus percentage 


\begin{tabular}{|c|c|c|c|c|c|c|c|c|}
\hline & \multirow[t]{2}{*}{ Total AS patients } & \multirow[t]{2}{*}{ Group $A(n=21)$} & \multirow[t]{2}{*}{ Group $B(n=42)$} & \multirow[t]{2}{*}{ Group $C(n=25)$} & \multirow{2}{*}{$\begin{array}{l}P \\
\text { value }\end{array}$} & \multicolumn{3}{|c|}{ Adjusted $P$ value } \\
\hline & & & & & & $A-B$ & $A-C$ & B-C \\
\hline ASDAS-ESR & $2.35(1.83,3.10)$ & $1.79(1.05-1.96)$ & $2.44(1.90-3.48)$ & $2.93(2.35-3.55)$ & $\begin{array}{l}< \\
0.001^{*}\end{array}$ & $\begin{array}{l}< \\
0.001^{*}\end{array}$ & $\begin{array}{l}< \\
0.001^{*}\end{array}$ & 0.443 \\
\hline ASDAS-CRP & $2.45(1.61,3.23)$ & $1.54(1.43,1.98)$ & $2.52(1.79,3.46)$ & $2.63(2.37,3.42)$ & $\begin{array}{l}< \\
0.001^{*}\end{array}$ & $\begin{array}{l}< \\
0.001^{*}\end{array}$ & $\begin{array}{l}< \\
0.001^{*}\end{array}$ & 0.538 \\
\hline SF-12PCS & $42.20(27.70,52.20)$ & $50.10(39.00,55.40)$ & $42.20(28.38,50.40)$ & $32.10(22.80,51.83)$ & $0.020^{*}$ & 0.092 & $0.020^{*}$ & 1.000 \\
\hline SF-12MCS & $42.75(27.50,53.50)$ & $52.20(40.00,54.75)$ & $42.35(29.45,53.50)$ & $31.90(25.40,51.75)$ & $0.038^{*}$ & 0.279 & $0.032^{*}$ & 0.675 \\
\hline HHS & $86.00(67.00,94.75)$ & $95.00(93.00,96.00)$ & $77.00(54.00,89.75)$ & $69.00(51.50,87.00)$ & $\begin{array}{l}< \\
0.001^{*}\end{array}$ & $\begin{array}{l}< \\
0.001^{*}\end{array}$ & $\begin{array}{l}< \\
0.001^{*}\end{array}$ & 0.875 \\
\hline BARSI & $2.00(1.00,3.00)$ & $1.00(1.00,1.00)$ & $2.00(1.00,2.00)$ & $3.00(3.00,4.00)$ & $\begin{array}{l}< \\
0.001^{*}\end{array}$ & $0.002^{*}$ & $\begin{array}{l}< \\
0.001^{*}\end{array}$ & $\begin{array}{l}< \\
0.001^{*}\end{array}$ \\
\hline HIMRISS & $29.63(15.25,43.00)$ & $14.50(11.38,22.25)$ & $29.38(17.00,40.94)$ & $38(31.13,64.38)$ & $\begin{array}{l}< \\
0.001^{*}\end{array}$ & $0.009^{\star}$ & $\begin{array}{l}< \\
0.001^{*}\end{array}$ & 0.103 \\
\hline \multicolumn{9}{|c|}{ 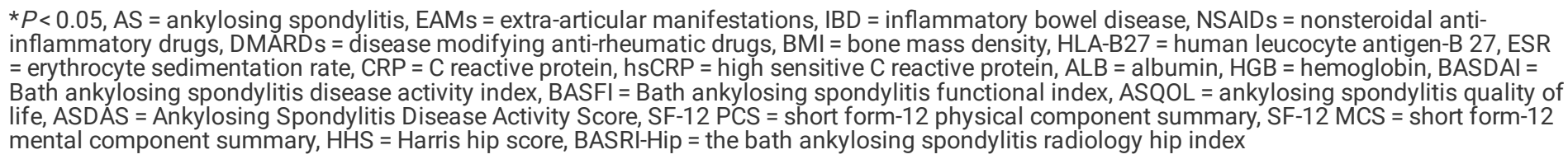 } \\
\hline \multicolumn{9}{|c|}{$\begin{array}{l}\text { Group A represents the hips with no hip involvement (HHS } \geq 80 \text { and BASRI } \leq 1) \text {, group B represents the hips with mild hip involvement (BASRI = } 2 \\
\text { or BASRI } \leq 1 \text { and HHS } \leq 79 \text { ) and Group C represents the hips with advanced hip involvement (BASRI } \geq 3 \text { ) }\end{array}$} \\
\hline $\begin{array}{l}\text { The value o } \\
\text { number plus }\end{array}$ & $\begin{array}{l}\text { luous variables } \mathrm{n} \\
\text { htage }\end{array}$ & ted as median & artile (25-75\%) & he categorical v & $\mathrm{w}$ & sed & & \\
\hline
\end{tabular}

\section{Radiographic Classification System}

The anteroposterior (AP) radiographs of the pelvis and MRI imaging were obtained on the same day on an outpatient basis. We excluded 8 patients whose radiographs were of inadequate quality and kept a total of 44 patients for review and analysis.

The BASRI hip system was adopted to assess the severity of radiological involvement in the hip joint $\mathbb{1 3}$, and it classified the status of the hip joints into a five-point scale from 0 to 4 ( 0 = normal, no change; 1 = suspicious, possible focal joint space narrowing; $2=$ minimal, circumferential joint space narrowing $>2 \mathrm{~mm} ; 3=$ moderate, circumferential joint space narrowing $\leq 2 \mathrm{~mm}$, or bone-on-bone apposition of $\leq 2 \mathrm{~cm}$; $4=$ severe, bone deformity or bone-on-bone apposition of $<2 \mathrm{~cm}$ or total hip re-placement).

MRI scans on enrolled patients' both hips were performed on a 3.0 T MR system (Siemens MAGNETOM Skyra, Siemens Company) using the following imaging parameters: a transverse T1-Weighted Spin Echo (T1 TSE) sequence, a transverse T2 TSE + Fat-Sat sequence, a coronal T1 TSE sequence, a coronal T2 TSE + Fat-Sat sequence, and trans-verse and coronal fat-saturated. All sequences used a $380 \mathrm{~mm}$ field of view, a $3.5 \mathrm{~mm}$ slice thickness, a $0.7 \mathrm{~mm}$ slice interval, a 384448 matrix, and several excitations (AVERAGE) of 2.

HIMRISS has three features: bone marrow lesions (BMLs), synovitis and effusion. BML is defined as an area of hyper-intensity within the bone in STIR sequence. The BML scoring on either femoral head or acetabulum side was graded according to the method which was described by Maksymowych et al $\mathbb{3} 3 \mathbb{}$. The range of BML scoring is $0-100$. Effusion and synovitis are scored together depending on the maximum depth of the fluid $(0=0-1.9 \mathrm{~mm}$, $1=2-3.9 \mathrm{~mm}, 2=\geq 4 \mathrm{~mm}$ ) on the same central, anterior and posterior slices. The range of total effusion scoring is 0 - 30 . Therefore, the final HIMRISS scoring range is $0-130$.

\section{Reading exercises}

Considering the possible effect of the raters' experiences on evaluating the hips, we chose four raters with different levels of training and experiences. A senior rheumatologist (L.H.C.) who is an attending physician with 16 years of clinical experience, an adult hip surgeon (Z.L.) who is a vice director with 15 years of clinical experience, and two musculoskeletal radiologists (Z.J., X.P.) who are residents with 4 years and 9 years of clinical experience respectively participated in grading the MRI imaging.

All raters were not informed about patient demographics and clinical parameters. Firstly, they learned the scoring rule through a PowerPoint file of Outcome Measures in Rheumatology (OMERACT) 11ヌ24囚individually. Then a training session was held where they agreed on a criteria for radiographic evaluation that was based on five MRI images.

Next, another $88 \mathrm{MRI}$ images from the PACS (Picture Archiving and Communication System) workstation which were not included in the evaluation were collected by the first author (M.S.L.) and were sent to the raters. Then they graded the MRI images in random sequences in different workrooms 
(exercise 1). Three months later, they repeated their works (exercise 2) without knowing the previous results to assess the reliability of test-retest.

\section{Statistical analysis}

Data were statistically analyzed using SPSS software for Windows (version 23.0; IBM, Armonk, NY, USA). Descriptive analyses for categorical variables were shown as percentages and frequencies and for continuous variables they were based on mean and standard deviation (SD) or median and quartile (25-75\%) if the data were skewed. The values of femoral BML, acetabular BML, synovitis effusion were summed up as the HIMRISS values for the single hip, and the mean values by all readers obtained in exercise 2 were taken as the final HIMRISS scores. The inter-rater and intra-rater reliability of HIMRISS were calculated using intraclass correlation coefficient (ICC). The correlations of HIMRISS with clinical continuous variables and with ordinal variables were determined by correlation coefficient $(r)$ in Pearson correlation analysis and Spearman rank correlation analysis respectively. We classified hips into no hip involvement group(HHS $\geq 80$ and BASRI $\leq 1)$ (Group A), mild hip involvement subgroup (BASRI = 2 or $B A S R I$ $\leq 1$ and HHS $\leq 79$ ) (Group B) and moderate to advanced hip involvement subgroup (BASRI $\geq 3$ ) (Group C) based on HHS of involved hip and BASRIhip score. Demographic features, clinical characteristics and radiographic parameters were compared using ANOVA (including post hoc analysis) and nonparametric Kruskal-Wallis test among these subgroups. Bonferroni method was taken to adjust the significance level in multiple comparisons. All reported $\mathrm{P}$ values were two-tailed with an alpha of 0.05 .

\section{Ethics and registration}

All procedures involving human participants carried out in the studies were in accordance with the ethical standards of the institutional and/or national research committee and the 1964 Helsinki declaration and its later amendments or comparable ethical standards. This study was approved by the Beijing Jishuitan Hospital Institutional Review Board (project number S-305/2007), and the informed consent was obtained from each participant before the enrollment of this study.

\section{Results}

\section{Patient demographics and clinical parameters}

The patient demographics and clinical parameters were displayed in Table 1. The results of BASRI-Hip score were as follows: 1 score in 33 hips (37.5\%), 2 in 30 hips (34.1\%), 3 in 18 hips (20.5\%) and 4 in 7 hips (8.0\%). The HHS was excellent for 30 hips (34.1\%), good for 18 (20.5\%), fair for 11 (12.5\%), and poor for 29 (33.0\%). Consequently, group A consisted of 21 hips, group B consisted of 42 hips and group C consisted of 25 hips.

\section{Reliability of HIMRISS scores}

The test-retest and interrater ICCs were provided in Table 2. The interrater ICCs were calculated by four raters in the second scoring exercise.

Table 2

The test-retest and interrater reliability of HIMRISS scores in AS patients $(\mathrm{N}=88)$

\begin{tabular}{|lcc|}
\hline & ICC & $95 \% \mathbf{C l}$ \\
\hline Test-retest & & \\
\hline Rheumatologist & 0.977 & $0.965-0.985$ \\
\hline Surgeon & 0.973 & $0.956-0.983$ \\
\hline Radiologists 1 & 0.959 & $0.938-0.973$ \\
\hline Radiologists 2 & 0.955 & $0.932-0.970$ \\
\hline Intrarater & & \\
\hline All four raters & 0.993 & $0.990-0.995$ \\
\hline HIMRISS = Hip inflammation MRI scoring system, ICC = intraclass correlation coefficient, $95 \% \mathrm{Cl}=95 \%$ confifidence interval \\
\hline
\end{tabular}

\section{Correlation analysis and intergroup comparisons}

The results of correlations between HIMRISS and the clinical and laboratory parameters were shown in Table 3. HIMRISS correlated moderately with BASDAI $(r=0.540, p<0.001)$, BASFI $(r=0.581, p<0.001)$, ASDAS-ESR $(r=0.604, p<0.001)$, ASDAS-CRP $(r=0.575, p<0.001)$. HIMRISS correlated weakly with ASQOL $(r=0.478, p<0.001)$, ESR $(r=0.426, p<0.001), \operatorname{CRP}(r=0.449, p<0.001)$, hsCRP $(r=0.398, p<0.001)$ and HHS $(r=-0.468, p<$ 0.001). 
Table 3

Correlations between HIMRISS score and clinical and laboratory parameters

\begin{tabular}{|c|c|c|}
\hline & Correlation coefficient & P value \\
\hline Age at outpatient visit (years) & -0.161 & 0.134 \\
\hline Age at onset (years) & -0.205 & 0.055 \\
\hline Disease duration (years) & 0.022 & 0.841 \\
\hline Diagnosis delay (years) & 0.091 & 0.398 \\
\hline Family history, n (\%) & 0.163 & 0.129 \\
\hline EAMs, n (\%) & 0.113 & 0.299 \\
\hline Uveitis, n (\%) & 0.154 & 0.152 \\
\hline IBD, n (\%) & -0.023 & 0.831 \\
\hline Psoriasis, n (\%) & 0.093 & 0.387 \\
\hline Use of NSAIDs, n (\%) & 0.068 & 0.527 \\
\hline Use of DMARDs, n (\%) & 0.005 & 0.966 \\
\hline BMI & -0.137 & 0.203 \\
\hline HLA-B27 positivity, n (\%) & -0.167 & 0.119 \\
\hline $\mathrm{ESR}(\mathrm{mm})$ & 0.426 & $<0.001^{\star}$ \\
\hline CRP (mg/L) & 0.449 & $<0.001^{\star}$ \\
\hline $\mathrm{hsCRP}(\mathrm{mg} / \mathrm{L})$ & 0.398 & $<0.001^{*}$ \\
\hline $\operatorname{ALB}(g / L)$ & -0.167 & 0.120 \\
\hline $\mathrm{HGB}(\mathrm{g} / \mathrm{L})$ & -0.267 & $0.012^{*}$ \\
\hline BASDAI & 0.540 & $<0.001^{*}$ \\
\hline BASFI & 0.581 & $<0.001^{\star}$ \\
\hline ASQOL & 0.478 & $<0.001^{*}$ \\
\hline ASDAS-ESR & 0.604 & $<0.001^{*}$ \\
\hline ASDAS-CRP & 0.575 & $<0.001^{\star}$ \\
\hline SF-12PCS & -0.270 & $0.011^{*}$ \\
\hline SF-12MCS & -0.222 & $0.037^{*}$ \\
\hline HHS & -0.468 & $<0.001^{\star}$ \\
\hline \multicolumn{3}{|c|}{ 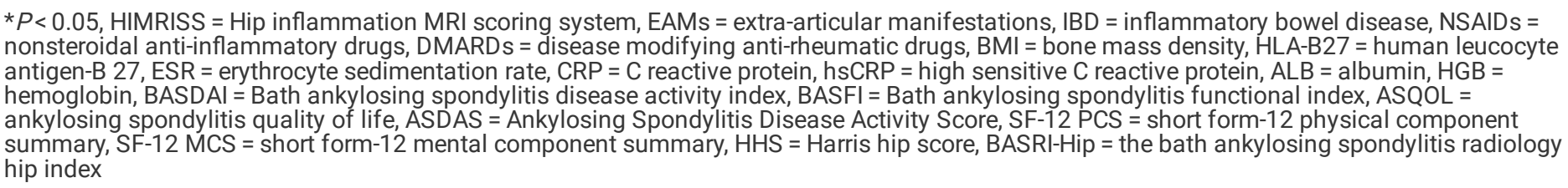 } \\
\hline \multicolumn{3}{|c|}{$\begin{array}{l}\text { Group A represents the hips with no hip involvement (HHS } \geq 80 \text { and BASRI } \leq 1) \text {, group B represents the hips with mild hip involvement (BASRI }=2 \\
\text { or BASRI } \leq 1 \text { and } \mathrm{HHS} \leq 79 \text { ) and Group } \mathrm{C} \text { represents the hips with advanced hip involvement (BASRI } \geq 3 \text { ) }\end{array}$} \\
\hline
\end{tabular}

The results of intergroup comparisons were provided in Table 1. HIMRISS of group B and group C was significantly higher than that of group A:

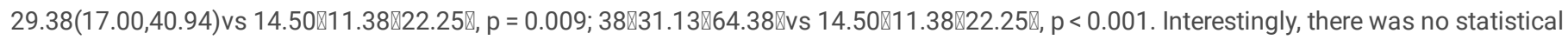
significance $(p=0.103)$ in the difference of HIMRISS between group B and group $C$.

\section{Discussion}


HIMRISS as a quantitative imaging method possess outstanding advantages in the assessment of early hip involvement in AS compared with the traditional MRI descriptive diagnosis. As far as we know, this was the first study which introduced the HIMRISS into this field.

Our study showed excellent reliability among four raters in AS patients. The intrarater ICC was 0.993 and interrater ICC was between 0.955 and 0.977.

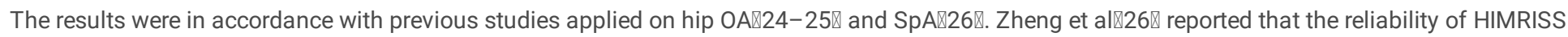
improved from 0.67 to 0.90 after two training sessions in cases with SpA. The reliability of detecting femoral BML, acetabular BML and synovitis effusion was very good after the two exercises (the overall ICC was $0.73,0.84$ and 0.88 , respectively).

The study conducted by Zheng et al $\mathrm{Q26}$ \ showed that it was more notable to see the correlations between disease activity and HIMRISS from bilateral rather than unilateral hip joint scores. The sum HIMRISS correlated moderately with ASDAS-CRP $(r=0.67, p<0.001)$ and CRP $(r=0.55, p<0.01)$ and weakly with ASDAS-ESR $(r=0.48, p<0.001)$. Unfortunately, the study did not discriminate the degree of radiographic hip involvement and as a result failed to confirm the clinical advantage of HIMRISS in detecting early hip inflammation lesions in SpA patients. In our series, there was a significant correlation of HIMRISS with BASDAI $(r=0.540, p<0.001)$, BASFI $(r=0.581, p<0.001)$, ASDAS-ESR $(r=0.604, p<0.001)$, ASDAS-CRP $(r=0.575, p<$

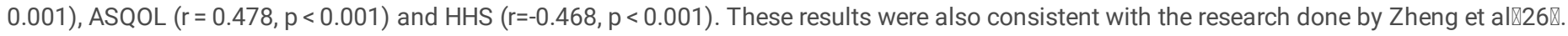

Moreover, we classified hips into no, mild and moderate to advanced hip involvement subgroups according to HHS of involved hip and BASRI-hip score. The mild hip involvement subgroup had a significantly higher HIMRISS than no hip involvement subgroup (29.38 vs $14.50, p=0.009)$. This result can be considered as further proof that HIMRISS is a reliable imaging tool to detect early hip structural damages in AS patients.

The main limitation to our study came from the nature of its single-center cross-sectional research. Relatively few participants took part in the study, which may have a negative impact on the evaluation of the rate and the degree of hip involvement in AS patients.

In conclusion, HIMRISS applied in patients with AS demonstrated a satisfying reliability, and it was in significant clinical association with a series of AS specified clinical and laboratory parameters. And there was a particular concern that the hips with mild hip involvement had a significantly higher HIMRISS than the ones without hip involvement. HIMRISS is a reliable quantitive assessment tool for evaluating early hip involvement in patients with AS.

\section{Conclusions}

The application of HIMRISS in patients with AS demonstrated a satisfactory reliability, which means it can be a reliable quantitive assessment tool for evaluating early hip involvement in patients with AS.

\section{Abbreviations}

AS

Ankylosing spondylitis; ASDAS:Ankylosing Spondylitis Disease Activity Score; ASQoL:Ankylosing Spondylitis Quality of Life; AP:anteroposterior; BASDAI:Bath Ankylosing Spondylitis Disease Activity Index; BASFI:Bath ankylosing spondylitis functional index; BASRI-hip:Bath Ankylosing Spondylitis Radilogy Index; BMI:Body Mass Index; BMLs:Bone Marrow Lesions; CRP:C reactive protein; DMARDs:Disease-modifying Anti-rheumatic Drugs; EAMs:Extra-articular Manifestations; ESR:Estrogen Receptor; HHS:Harris Hip Scoring; HIMRISS:Hip Inflammation MRI Scoring System; HLA:Human leukocyte antigen; ICCs:Intraclass Correlation Coefficients; MRI:Magnetic resonance imaging; NSAIDs:Non-steroidal anti-inflammatory drugs; OA:Osteoarthritis; PROs:Patient-reported Outcomes; SF-12:Short Form-12; SpA:Spondyloarthritis; THA:Total Hip Arthroplasty; T1 TSE:T1Weighted Spin Echo.

\section{Declarations}

\section{Ethics approval and consent to participate}

All procedures involving human participants carried out in the studies were in accordance with the ethical standards of the institutional and/or national research committee and the 1964 Helsinki declaration and its later amendments or comparable ethical standards. This study was approved by the Beijing Jishuitan Hospital Institutional Review Board (project number S-305/2007), and the informed consent was obtained from each participant before the enrollment of this study.

\section{Consent for publication}

Not applicable.

\section{Availability of data and materials}

The datasets used and/or analyzed during the current study are available from the corresponding author on reasonable request.

\section{Competing interests}


All authors do not have any conflicts of interest.

\section{Funding}

No funding was obtained for this study.

\section{Authors' contributions}

All authors were involved in the drafting of this article or the critical revising for the important intellectual content, and all authors approved the final version to be published. All authors had full access to all the data in the study and are responsible for the integrity of the data and the accuracy of data analysis.

Study conception and design. Liang Zhang and Yixin Zhou

Acquisition of data. Siliang Man and Liang Zhang.

Analysis and interpretation of data. Siliang Man and Liang Zhang.

\section{Acknowledgements}

The authors would like to thank Dr. Jiao Zhao and Dr. Peng Xu for their help with the grading of the MRI imaging.

\section{References}

1. Burki V, Gossec L, Payet J, Durnez A, Elhai M, Fabreguet I, Koumakis E, Meyer M, Paternotte S, Roure F, Dougados M. Prevalence and charac $\neg$ teristics of hip involvement in spondyloarthritis: a single-centre observational study of 275 patients. Clin Exp Rheumatol 2012;30:481486.

2. Chen HA, Chen $\mathrm{CH}$, Liao HT, Lin YJ, Chen PC, Chen WS, Chou CT. Factors associated with radiographic spinal involvement and hip involvement in ankylosing spondylitis. Semin Arthritis Rheum 2011;40:552-558.

3. Vander Cruyssen B, Muñoz-Gomariz E, Font P, Mulero J, de Vlam K, Boonen A, Vazquez-Mellado J, Flores D, Vastesaeger N, Collantes E; ASPECTREGISPONSER-RESPONDIA working group. Hip involvement in ankylosing spondylitis: epidemiology and risk factors associated with hip replacement surgery. Rheumatology (Oxford) 2010;49:73-81.

4. Guan M, Wang J, Zhao L, Xiao J, Li Z, Shi Z. Management of hip involvement in ankylosing spondylitis. Clin Rheumatol 2013;32:1115-1120.

5. Zhao J, Zheng W, Zhang C, Li J, Liu D, Xu W. Radiographic hip involvement in ankylosing spondylitis: factors associated with severe hip diseases. J Rheumatol 2015;42(1):106-110. doi: 10.3899/jrheum.140428.

6. Vander Cruyssen B, Vastesaeger N, Collantes-Estévez E. Hip disease in ankylosing spondylitis. Curr Opin Rheumatol 2013;25:448-54. doi: 10.1097/BOR.0b013e3283620e04.

7. Gautam D, Malhotra R. Total Hip Arthroplasty in Ankylosing Spondylitis With Extension Contracture of Hips. J Arthroplasty 2019;34:71-76. doi: 10.1016/j.arth.2018.08.025.

8. Zhang L, Yang D, Yin X, Zhou Y. Risk factors for poor hip flexion after total hip arthroplasty for the treatment of ankylosing spondylitis a multivariate analysis. Clin Rheumatol 2014;33:1295-1301.

9. Goodman SM, Zhu R, Figgie MP, Huang WT, Mandl LA. Short-term total hip replacement outcomes in ankylosing spondylitis. J Clin Rheumatol. 2014;20(7):363-368. doi: 10.1097/RHU.0000000000000138.

10. Bhan S, Eachempati KK, Malhotra R. Primary Cementless Total Hip Arthroplasty for Bony Ankylosis in Patients with Ankylosing Spondylitis. J Arthoplasty 2008; 23: 859-866.

11. Joshi AB, Markovic L, Hardinge K, Murphy JC. Total hip arthroplasty in ankylosing spondylitis: an analysis of 181 hips. J Arthroplasty 2002;17:427-433.

12. Tang WM, Chiu KY. Primary total hip arthroplasty in patients with ankylosing spondylitis. J Arthroplasty 2000;15:52-58.

13. MacKay K, Mack C, Brophy S, Calin A. The Bath Ankylosing Spondylitis Radiology Index (BASRI): a new, validated approach to disease assessment. Arthritis Rheum 1998; 41:2263-2270.

14. Mackay K, Brophy S, Mack C, Doran M, Calin A. The development and validation of a radiographic grading system for the hip in ankylosing spondylitis: the Bath Ankylosing Spondylitis. Radiology Hip Index. J Rheumatol 2000;27:2866-2872.

15. Braun J, Golder W, Bollow M, et al. Imaging and scoring in ankylosing spondylitis. Clin Exp Rheumatol $2002 ; 20$ (6 Suppl 28):S178-S184.

16. Jang JH, Ward MM, Rucker AN, et al. Ankylosing spondylitis: patterns of radiographic involvement: a re-examination of accepted principles in a cohort of 769 patients. Radiology 2010; 258:192-198.

17. Appel H, Kuhne M, Spiekermann S, et al. Immunohistochemical analy-sis of hip arthritis in ankylosing spondylitis. Arthritis and Rheumatism 2006;54:1805-1813. 
18. Chen WS, Chen $\mathrm{CH}$, Lin KC, et al. Immunohistological features of hip synovitis inankylosing spondylitis with advanced hip involvement. Scandinavian Journal of Rheumatology 2009;38:154-155.

19. Rudwaleit M, Jurik AG, Hermann KG, et al. Defining active sacroiliitis on magnetic resonance imaging (MRI) for classification of axial spondyloarthritis: a consensual approach by the ASAS/OMERACT MRI group. Ann Rheum Dis 2009;68:1520-1527.

20. Chary-Valckenaere I, d'Agostino MA, Loeuille D. Role for imaging studies in ankylosing spondylitis. Joint Bone Spine. 2011;78(2):138-143. doi: 10.1016/j.jbspin.2010.07.008.

21. Yilmaz MH, Ozbayrak M, Kasapcopur O, et al. Pelvic MRI findings of juvenile-onset ankylosing spondylitis. Clin Rheumatol 2010; 29:1007-1013.

22. Mager AK, Althoff CE, Sieper J, et al. Role of whole-body magnetic resonanceimaging in diagnosing early spondyloarthritis. European Journal of Radiology 2009;71:182-188.

23. Huang ZG, Zhang XZ, Hong W, Wang GC, Zhou HQ, Lu X, Wang W. The application of MR imaging in the detection of hip involvement in patients with ankylosing spondylitis. Eur J Radiol 2013;82(9):1487-1493. doi: 10.1016/j.ejrad.2013.03.020.

24. Maksymowych W, Pitts M, Budak MJ, Gracey D, Lambert RG, McDougall D, Pianta M, Rennie WJ, Wichuk S, Winn N, Jaremko JL. Development and Preliminary Validation of a Digital Overlay-based Learning Module for Semiquantitative Evaluation of Magnetic Resonance Imaging Lesions in Osteoarthritis of the Hip. J Rheumatol 2016;43(1):232-238. doi: 10.3899/jrheum.141574.

25. Jaremko JL, Lambert RG, Zubler V, Weber U, Loeuille D, Roemer FW, Cibere J, Pianta M, Gracey D, Conaghan P, Ostergaard M, Maksymowych WP. Methodologies for semiquantitative evaluation of hip osteoarthritis by magnetic resonance imaging: approaches based on the whole organ and focused on active lesions. J Rheumatol 2014;41(2):359-369. doi: 10.3899/jrheum.131082.

26. Zheng Y, Zhang K, Han Q, Hao Y, Liu Y, Yin H, Ding J, Zheng Z, Leng N, Jia J, Wu Z, Zhu P. Application and preliminary validation of the hip inflammation MRI scoring system (HIMRISS) in spondyloarthritis. Int J Rheum Dis 2019;22(2):228-233. doi: 10.1111/1756-185X.13451.

27. Moll JM, Wright V. New York clinical criteria for ankylosing spondylitis: a statistical evaluation. Ann Rheum Dis 1973; 12:354-363.

28. Garrett S, Jenkinson T, Kennedy LG et al (1994) A new approach to defining disease status in ankylosing spondylitis: the Bath Ankylosing Spondylitis Disease Activity Index. J Rheumatol 21:2286-2291.

29. Lukas C, Landewé R, Sieper J, Dougados M, Davis J, Braun J, van der Linden S, van der Heijde D; Assessment of SpondyloArthritis international Society. Development of an ASAS-endorsed disease activity score (ASDAS) in patients with ankylosing spondylitis. Ann Rheum Dis. 2009 Jan;68(1):18-24. doi: 10.1136/ard.2008.094870.

30. Calin A, Garrette S, Whitelock H et al (1994) A new approach to defining functional ability in ankylosing spondylitis. The Bath Ankylosing Spondylitis Functional Index. J Rheumatol 21:2281-2285.

31. Leung YY, Lee W, Lui NL, Rouse M, McKenna SP, Thumboo J. Adaptation of Chinese and English versions of the Ankylosing Spondylitis quality of life (ASQoL) scale for use in Singapore. BMC Musculoskelet Disord. 2017;18(1):353.

32. Busija L, Pausenberger E, Haines TP, Haymes S, Buchbinder R, Osborne RH. Adult measures of general health and health-related quality of life: Medical Outcomes Study Short Form 36-Item (SF-36) and Short Form 12-Item (SF-12) Health Surveys, Nottingham Health Profile (NHP), Sickness Impact Profile (SIP), Medical Outcomes Study Short Form 6D (SF-6D), Health Utilities Index Mark 3 (HUI3), Quality of Well-Being Scale (QWB), and Assessment of Quality of Life (AQoL). Arthritis Care Res (Hoboken). 2011;63 Suppl 11:S383-412.

33. Harris WH. Traumatic arthritis of the hip after dislocation and acetabular fractures: treatment by mold arthroplasty. An endresult study using a new method of result evaluation. J Bone Joint Surg Am. 1969;51:737-755.

34. Maksymowych WP, Cibere J, Loeuille D, Weber U, Zubler V, Roemer FW, Jaremko JL, Sayre EC, Lambert RG. Preliminary validation of 2 magnetic resonance image scoring systems for osteoarthritis of the hip according to the OMERACT filter. J Rheumatol. 2014;41(2):370-8. doi: 10.3899/jrheum.131083. 